\title{
Supporting Information for Rational Modulation of pH-triggered Macromolecular Poration by Peptide Acylation and Dimerization
}

Eric $\mathrm{Wu}^{\dagger}$, Ramsey M. Jenschke ${ }^{\dagger}$, Kalina Hristova ${ }^{\ddagger}$, William C Wimley ${ }^{\dagger *}$

† Department of Biochemistry and Molecular Biology, Tulane University School of Medicine, New Orleans, Louisiana, 70112, United States. ‡ Department of Materials Science and Engineering and Institute for NanoBioTechnology, Johns Hopkins University, Baltimore, MD, 21218, United States.

AUTHOR INFORMATION

Corresponding Author

William C. Wimley - Department of Biochemistry and Molecular Biology, Tulane University School of Medicine, New Orleans, Louisiana, 70112, United States. Email: wwimley@tulane.edu.Phone: 504-988-7076 

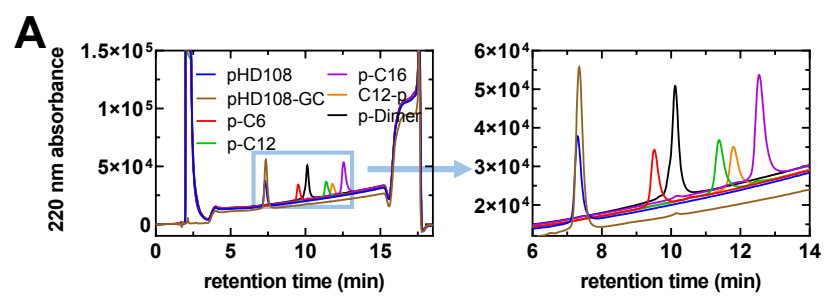

\begin{tabular}{|l|c|c|}
\hline B & $\begin{array}{c}\text { expected MALDI- } \\
\text { TOF reading } \\
\text { (MW + 1) }\end{array}$ & $\begin{array}{c}\text { MALDI-TOF } \\
\text { result }\end{array}$ \\
\hline pHD108-GC & 3039 & 3038.8 \\
\hline p-C6 & 3156 & 3155.2 \\
\hline p-C12 & 3241 & 3239.9 \\
\hline p-C16 & 3295 & 3295.6 \\
\hline C12-p & 3061 & 3061 \\
\hline p-Dimer & 6076 & 6079.3 \\
\hline
\end{tabular}

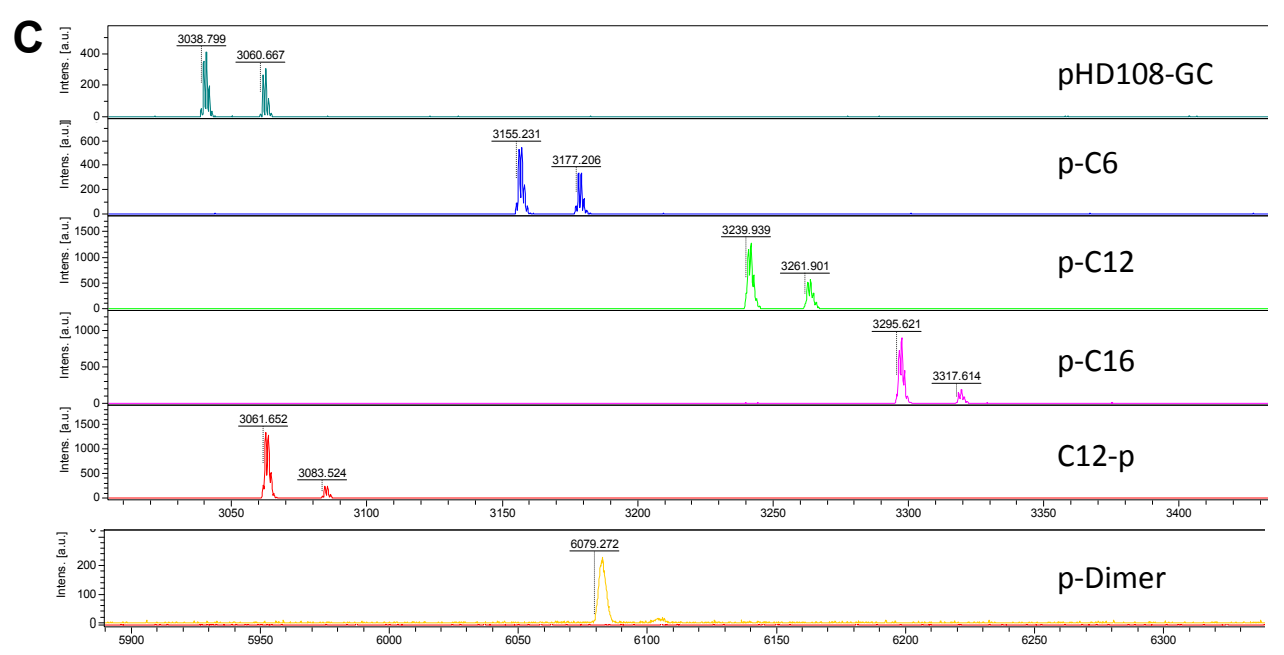

Figure S1. Validation of variant purity and identity. (A) HPLC was used to purify the variants.

HPLC traces of the purified variants showed that they were $>95 \%$ pure. $(B, C)$ Subsequent

MALDI-TOF mass spectrometry was used to confirm the correct mass of the variants. The +22

masses are expected sodium adducts. 

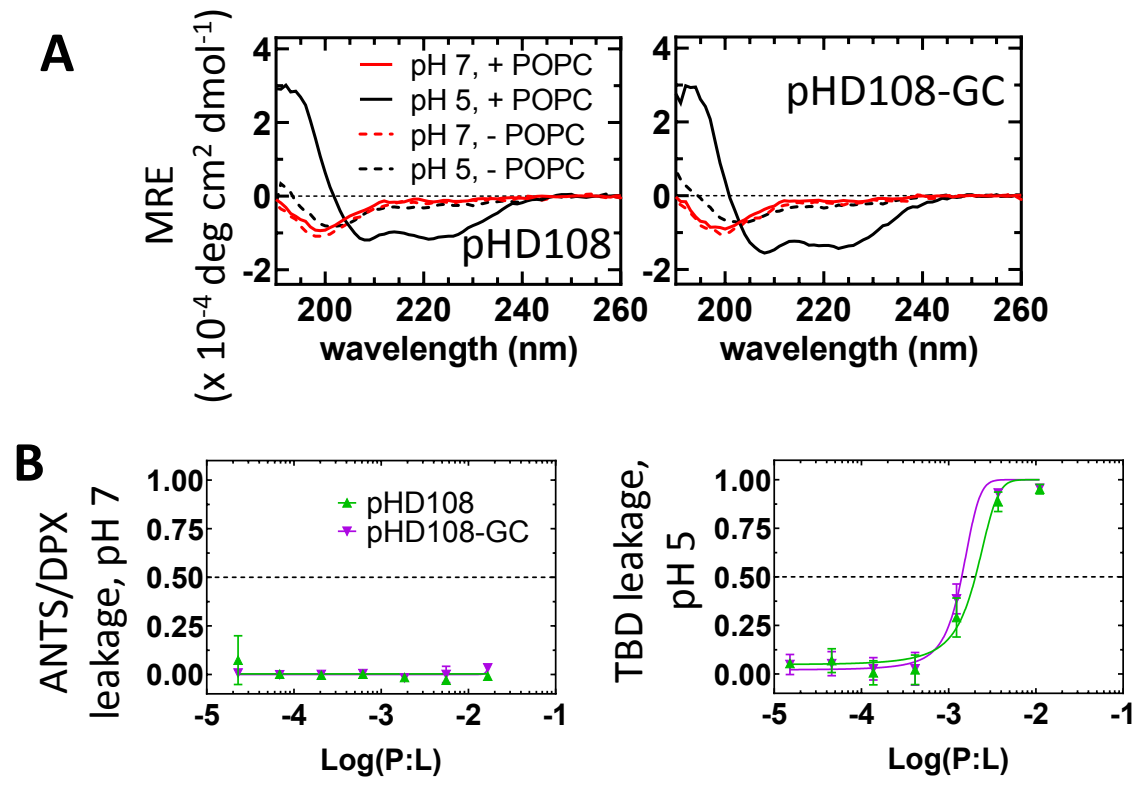

Figure S2. pHD108-GC has nearly identical characteristic as pHD108. (A) Since pHD108-GC was used for conjugations, we tested the secondary structure characteristics with circular dichroism and see that the two peptides behave nearly identically. (B) We also see that leakage activity is nearly identical as well. The impact of a glycine-cysteine modification at the C-terminus seems to be minimal. Variants can therefore be directly compared to pHD108 peptide.
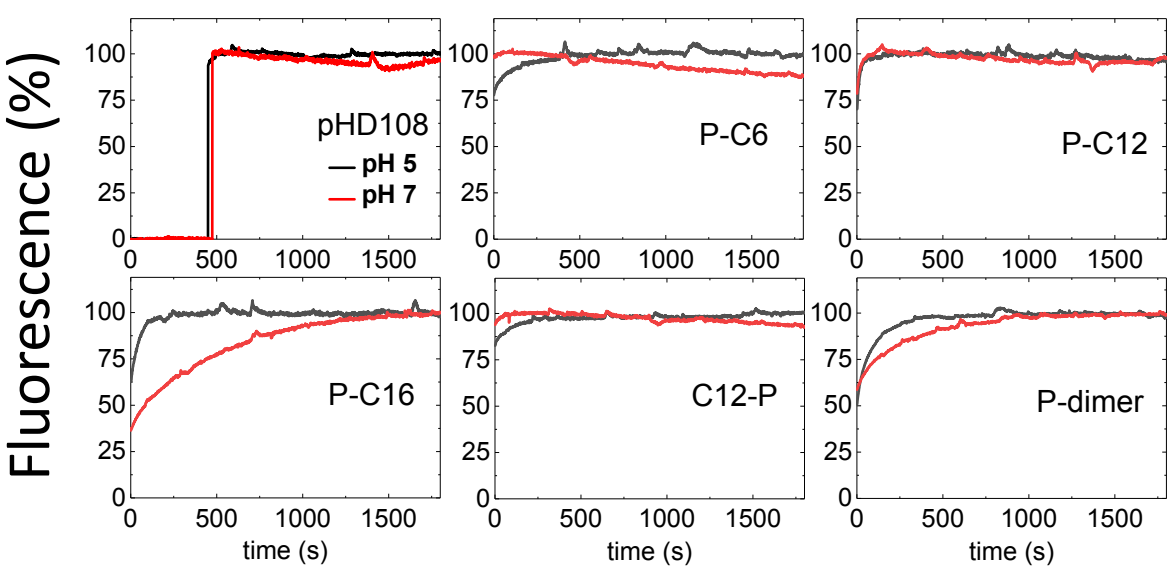
Figure S3. Tryptophan fluorescence intensity measured over time. POPC vesicles were added at $\sim 500 \mathrm{~s}$ for $\mathrm{pHD} 108$. All others had vesicles added at $0 \mathrm{~s}$.
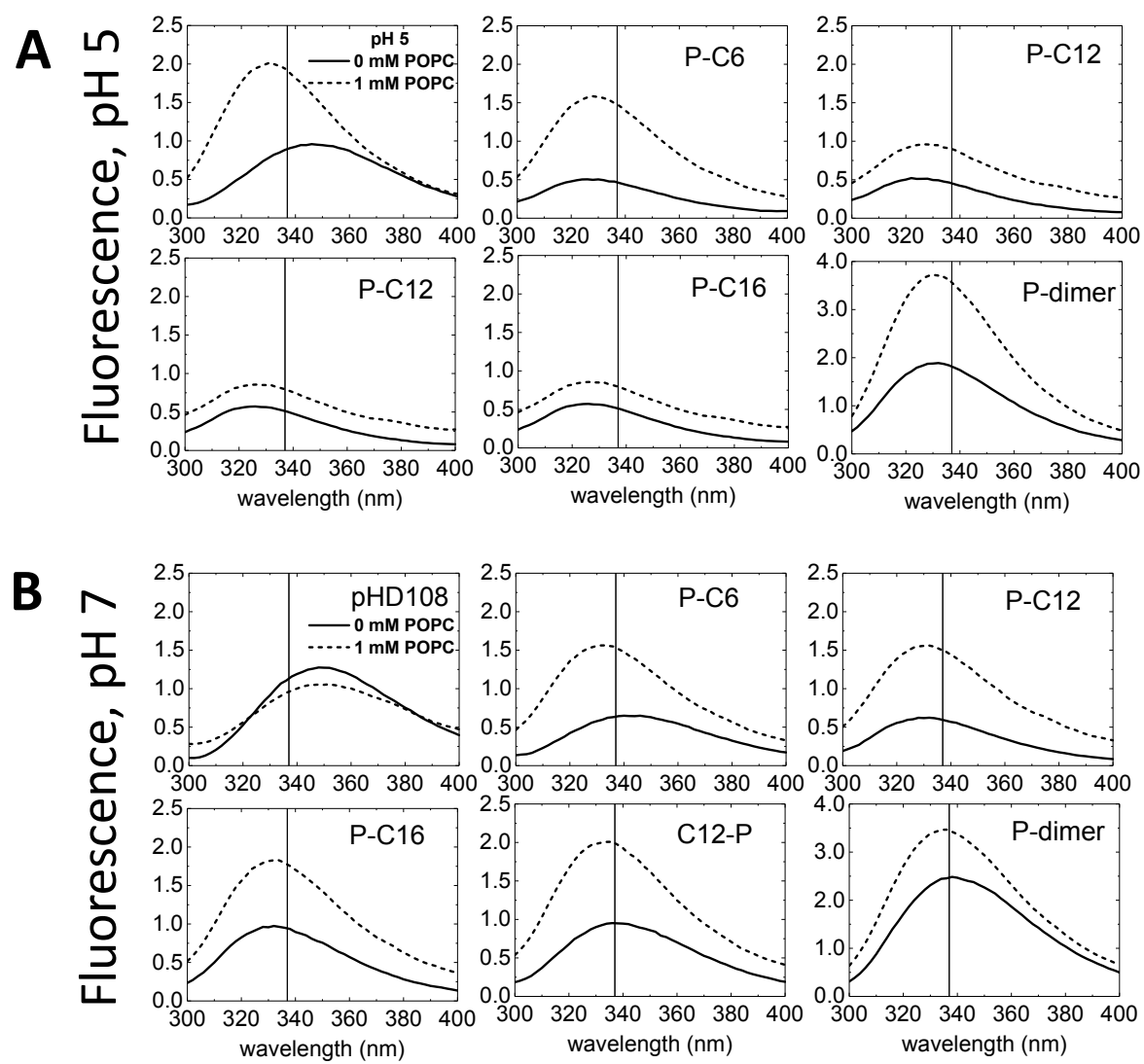

Figure S4. Tryptophan fluorescence emission spectra with 0 and $1 \mathrm{mM} \mathrm{POPC}$ vesicles. (a)

Spectra at pH 5. (b) Spectra at $\mathrm{pH} 7$. Vertical line is at $337 \mathrm{~nm}$ for reference. 

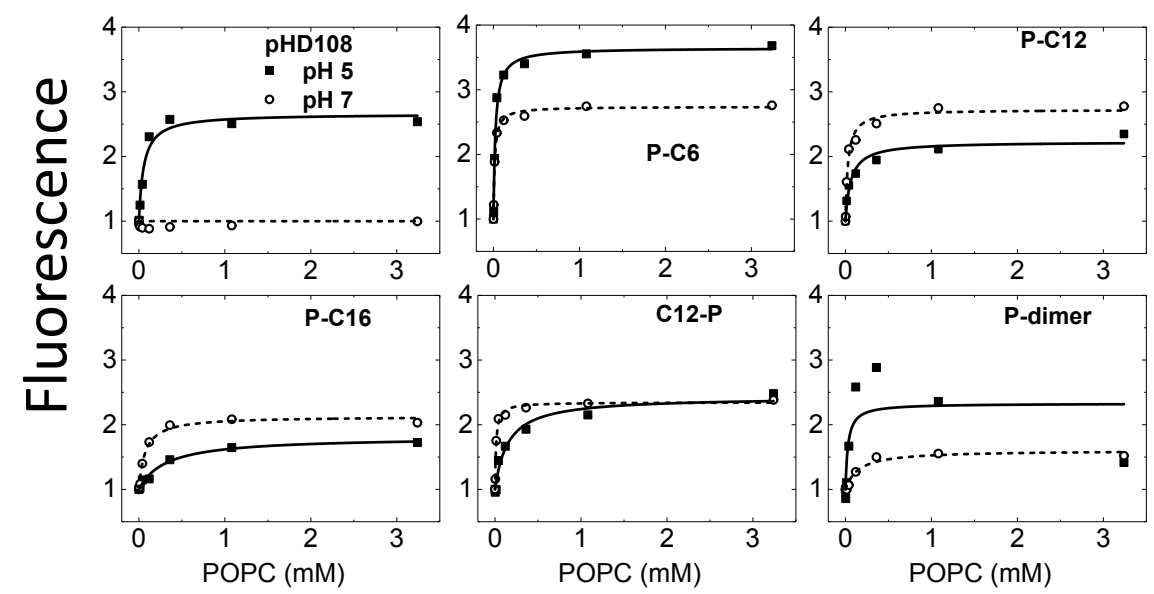

Figure S5. Binding curves of Trp fluorescence intensity at $334 \mathrm{~nm}$ for conjugates as POPC vesicle concentration is increased. This data was used to calculate mole fraction partition coefficients.

\begin{tabular}{|c|c|c|c|c|c|c|c|c|c|c|}
\hline & \multicolumn{5}{|c|}{ pH 5} & \multicolumn{5}{|c|}{$\mathrm{pH} 7$} \\
\hline & $\begin{array}{c}K_{x} \\
\left(x 10^{6}\right)\end{array}$ & $\begin{array}{c}\Delta \mathrm{G}^{\circ} \\
(\mathrm{kcal} / \mathrm{mol})\end{array}$ & $\begin{array}{c}\text { Rate } \\
\text { constant } \\
\left(\sec ^{-1}\right)\end{array}$ & $\begin{array}{c}\text { LIC }_{50} \\
\text { ANTS/DPX } \\
\left.\text { (P:L } \times 10^{-3}\right)\end{array}$ & $\begin{array}{l}\mathrm{LIC}_{50}, \mathrm{TBD} \\
\left(\mathrm{P}: \mathrm{L} \times 10^{-3}\right)\end{array}$ & $\begin{array}{c}K_{x} \\
\left(x 10^{6}\right)\end{array}$ & $\begin{array}{c}\Delta \mathrm{G}^{\circ} \\
(\mathrm{kcal} / \mathrm{mol})\end{array}$ & $\begin{array}{c}\text { Rate } \\
\text { constant } \\
\left(\sec ^{-1}\right)\end{array}$ & $\begin{array}{c}\text { LIC }_{50} \\
\text { ANTS/DPX } \\
\left.\text { (P:L } \times 10^{-3}\right)\end{array}$ & $\begin{array}{l}\mathrm{LIC}_{50}, \mathrm{TBD} \\
\left(\mathrm{P}: \mathrm{L} \times 10^{-3}\right)\end{array}$ \\
\hline pHD108 & 1.01 & -8.18 & $>2.3$ & 0.85 & 2.87 & --- & ---- & $>2.3$ & $>50$ & $>50$ \\
\hline P-C6 & 3.88 & -8.98 & 0.033 & 0.24 & 2.24 & 2.47 & -8.71 & $>2.3$ & 3.01 & 2.64 \\
\hline P-C12 & 1.97 & -8.58 & 0.116 & 0.89 & 10.0 & 0.90 & -8.11 & 0.165 & 2.26 & 1.49 \\
\hline P-C16 & 0.77 & -8.02 & 0.036 & 2.93 & $>50$ & 0.18 & -7.15 & 0.0028 & 0.97 & 0.79 \\
\hline C12-P & 0.37 & -7.58 & 0.048 & 0.43 & 5.36 & 4.42 & -9.06 & $>2.3$ & 6.17 & 3.26 \\
\hline P-dimer & 0.37 & -7.60 & 0.015 & 0.73 & 0.50 & 1.90 & -8.56 & 0.0054 & 31.5 & 36.1 \\
\hline
\end{tabular}

Table S1. Table of properties for pHD108 variants. Included are partition coefficients $\left(K_{x}\right)$, Gibbs free energy $\left(\Delta G^{\circ}\right)$, rate constants, and half maximal leakage (P:L). 